\title{
A INFLUÊNCIA DA GESTÃO DE RECURSOS HUMANOS NO DESEMPENHO AMBIENTAL NO SETOR METAL MECÂNICO BRASILEIRO
}

\author{
THE INFLUENCE OF HUMAN RESOURCES \\ MANAGEMENT IN ENVIRONMENTAL PERFORMANCE \\ IN THE BRAZILIAN METAL MECHANICAL INDUSTRY
}

Data de submissão: 17-05-2015 Aceite: $30-06-2015$

Wesley Ricardo de Souza Freitas ${ }^{1}$

Cláudia Terezinha Kniess ${ }^{2}$

Tatiana Tucunduva Philippi Cortese ${ }^{3}$

Dirceu da Silva ${ }^{4}$

\section{RESUMO}

A preservação do meio ambiente é uma preocupação de todos os setores da sociedade. No meio empresarial, a área de recursos humanos pode contribuir para o desempenho ambiental por meio das suas práticas. Assim, este artigo tem como objetivo identificar se as práticas de gestão de recursos humanos (GRH) influenciam o desempenho ambiental no setor metalomecânico em empresas vinculadas à Associação Brasileira da Indústria de Máquinas e Equipamentos (ABIMAQ). Como procedimentos metodológicos, realizouse um survey junto a uma amostra de 108 empresas, analisando-se os resultados por meio da Partial Least Squares (PLS). Os resultados indicaram que a gestão de recursos humanos verde (GRHV), por meio de práticas como recrutamento e seleção, treinamento, avaliação de desempenho e recompensas, proporciona uma influência positiva e significativa sobre a redução do consumo de recursos naturais como água, energia e matéria-prima, bem como sobre a redução na geração de resíduos sólidos e efluentes, aspectos ambientais que formam o desempenho ambiental na amostra das empresas do setor metalomecânico.

Palavras-chave: gestão ambiental; gestão de recursos humanos; gestão de recursos humanos verde.

\footnotetext{
${ }^{1}$ Possui graduação em Administração pela Universidade Federal de Mato Grosso do Sul - UFMS, mestrado em Engenharia de Produção pela Universidade Estadual Paulista Júlio de Mesquita Filho - UNESP e doutorado em Administração pela Universidade Nove de Julho - UNINOVE. Atualmente é professor na Universidade Federal de Mato Grosso Sul - Campus de Paranaíba (UFMS/CPAR). Paranaiba. Mato Grosso do Sul. Brasil. E-mail: wesley007adm@gmail.com

${ }_{2}^{2}$ Possui graduação em Bacharelado em Química pela Universidade Federal de Santa Catarina - UFSC, graduação em Formação Pedagógica para Formadores da Educação pela Universidade do Sul de Santa Catarina - UNISUL, mestrado em Engenharia Química pela Universidade Federal de Santa Catarina - UFSC e doutorado em Ciência e Engenharia de Materiais pela Universidade Federal de Santa Catarina - UFSC. Atualmente é docente e pesquisadora da Universidade Nove de Julho (UNINOVE/SP) no Programa de Pós-graduação em Administração e no Programa de Mestrado Profissional em Administração - Gestão de Projetos e coordenadora do Programa de Mestrado Profissional em Administração - Gestão Ambiental e Sustentabilidade da UNINOVE. São Paulo. São Paulo. Brasil. E-mail: kniesscl@gmail.com

${ }^{3}$ Possui graduação em Direito pelo Centro Universitário das Faculdades Metropolitanas Unidas -FMU, mestrado em Saúde Pública pela Universidade de São Paulo - USP e doutorado em Saúde Pública pela Universidade de São Paulo - USP. Atualmente é docente do Programa de Mestrado Profissional em Administração - Gestão Ambiental e Sustentabilidade da UNINOVE, do Programa de Mestrado Acadêmico Cidades Inteligentes e Sustentáveis da UNINOVE e docente do Centro Universitário SENAC. São Paulo. São Paulo. Brasil. E-mail: taticortese@gmail.com

${ }^{4}$ Possui graduação em Física pela Universidade de São Paulo - USP, mestrado em Física pela Universidade de São Paulo - USP e doutorado em Educação pela Universidade de São Paulo - USP. Atualmente é professor do Programa de Pós-Graduação em Administração da Universidade Nove de Julho - UNINOVE e da Universidade Estadual de Campinas - UNICAMP. São Paulo. São Paulo. Brasil. E-mail: dirceuds@gmail.com
} 


\section{ABSTRACT}

The environmental protection is a concern of all sectors of society. In the business environment, human resources can contribute to environmental performance through its Human Resources practices. Thus, this article aims to identify whether human resource management practices influence the environmental performance in the mechanical metal sector companies linked to the Brazilian Association of Machinery and Equipment (ABIMAQ). As methodological procedures, we carried out a survey with a sample of 108 companies, analyzing the results through the Partial Least Squares (PLS). The results indicated that from the management of green human resources, through practices such as recruitment and selection, training, performance evaluation and rewards, there is a positive and significant influence on reducing the consumption of natural resources such as water, energy, matter raw and reduction in the generation of solid waste and wastewater, environmental aspects that form the environmental performance of companies in the sample of the Mechanical Metal Sector.

Keywords: environmental management; human resources management; green human resources management

\section{INTRODUÇÃO}

Nos últimos 200 anos, o crescimento industrial elevou o padrão e a qualidade de vida de muitas sociedades ao redor do mundo. Entretanto, esse crescimento, muitas vezes, ocorreu à custa da degradação do ambiente natural (DAILY; HUANG, 2001), que está se tornando uma das principais preocupações da sociedade (MURILLO-LUNA; GÁRCES-AYERBE; RIVERA-TORRES, 2011). Inúmeros problemas ambientais no planeta, como o aumento da poluição, que tem como consequências chuvas ácidas, derretimento glacial, evaporação das águas e temperaturas elevadas,sãodecorrentesdo uso desordenado dos recursos naturais (GOONSEN, 2012).

Tradicionalmente, apenas o desempenho econômico já garantia a prosperidade das empresas e dos seus acionistas, mas, atualmente, os resultados financeiros são acompanhados por uma maior atenção aos aspectos sociais e ambientais da organização (SUDIN, 2011). Nesse contexto, as organizações devem atuar de forma responsável em relação ao meio ambiente, utilizando os recursos naturais e as matérias-primas de forma consciente, prevenindo e reduzindo a poluição, bem como preservando os ecossistemas, por meio da inserção da questão ambiental nos valores organizacionais, a qual deve ser operacionalizada pela gestão ambiental. Daily e Huang (2001) reconhecem esta necessidade e sugerem a realização de mais pesquisas no âmbito organizacional a fim de direcionar novos rumos para a sustentabilidade ambiental.

Nesse sentido, a gestão de recursos humanos (GRH) exerce um papel importante na implementação de mudanças e incorporação de novas demandas nas empresas por meio das práticas de RH. Entretanto, a interseção da sustentabilidade ambiental com a GRH é uma área recente que está em ascensão, caracterizada pela carência de literatura consolidada (JACKSON et al., 2011).

Nesse ponto de vista, a gestão de recursos humanos verde (GRHV) consiste na inserção de objetivos e metas ambientais nas práticas funcionais de recrutamento, seleção, treinamento, avaliação de desempenho e recompensas, com a finalidade de diminuir os impactos ambientais, contribuindo para uma cultura organizacional sustentável e a melhora do desempenho ambiental.

Dentro de uma perspectiva evolutiva, há autores que percebem a GRH como o centro da sustentabilidade organizacional (JABBOUR; SANTOS, 2008; RIMANOCZY; PEARSON, 2010; FREITAS; JABBOUR; SANTOS, 2011). Além disso, a integração da GRH e da gestão ambiental foi tema de diversos call for papers: German Journal of Researchon Human Resource Management (MULLER-CAMEN et. al, 2011), Journal Human Resource Management (TAYLOR; EGRI; OSLAND, 2012) e The Interna- 
tional Journal of Human Resource Management (RENWICK et al., 2012), destacando a relevância do entrelaçamento da GRH com a gestão ambiental. Dessa forma, a integração da GRH com a gestão ambiental, apesar de "ser frequentemente apontada como necessária, ela também é percebida como escassa, teórica e empiricamente" (JABBOUR; SANTOS, 2013, p. 504).

Logo, a partir da investigação das práticas de recursos humanos e das práticas de gestão ambiental no setor metalomecânico, objeto deste estudo, espera-se encontrar evidências da contribuição da GRH para o desempenho ambiental das empresas do setor, pois os insumos utilizados e os resíduos gerados durante os processos industriais causam um impacto ambiental significativo (SENAI, 2008). Além disso, as atividades desse setor são consideradas de alto impacto ambiental, sendo alvo constante da sociedade e dos órgãos reguladores devido ao alto risco de poluição ambiental (CERVELINI; SOUZA, 2008), especialmente pelas emissões atmosféricas, pelos efluentes líquidos, pelos resíduos sólidos, pela poluição sonora e pelo consumo de água e de energia elétrica (CHAIB, 2005). O setor é enquadrado como de médio a alto impacto ambiental e utilizador dos recursos naturais (Indústria Metalúrgica e Mecânica) pela Lei Federal n. ⒑165, de 27 de dezembro de 2000, que altera a Política Nacional de Meio Ambiente, criando a Taxa de Controle e Fiscalização Ambiental (TCFA) e estabelecendo, em seu anexo VIII, as categorias das atividades potencialmente poluidoras e utilizadoras de recursos ambientais.

Diante dessa problematização, emana a questão de pesquisa deste trabalho a partir de dois eixos temáticos, a GRH e a gestão ambiental: "as práticas de GRH influenciam o desempenho ambiental de empresas do setor metalomecânico vinculadas à Associação Brasileira da Indústria de Máquinas e Equipamentos (ABIMAQ)"?. Para atender ao objetivo proposto, realizou-se uma pesquisa exploratório-descritiva, a partir de um levantamento junto a uma amostra de 108 empresas do setor metalomecânico, analisando-se os resultados pro meio da Partial Least Squares (PLS.)

Este artigo está estruturado em cinco partes, além desta introdução. Na seção 2, apresenta-se o pano de fundo teórico. Na seção 3, destacam-se os procedimentos metodológicos e operacionais de coleta de dados. Os resultados são apresentados na seção 4 e discutidos à luz da literatura na seção 5. Por fim, apresentam-se as considerações finais da pesquisa, indicando suas contribuições, sugestões e limitações.

\section{REFERENCIAL TEÓRICO}

Nesta seção, são apresentados os conceitos sobre gestão de recursos humanos verde (GRHV).

\subsection{Gestão de recursos humanos verde}

A gestão de recursos humanos (GRH) pode exercer um papel determinante na construção de uma cultura voltada à organização sustentável. Entretanto, desenvolver e educar os funcionários em uma nova cultura pode consumir um esforço considerável de tempo em curto prazo, porém, em longo prazo, resultados positivos podem ser obtidos (SROUFEE et al., 2010). Segundo esses autores, não basta apenas falar de sustentabilidade, pois a empresa deve apresentar políticas que conjuguem a retórica com a prática empresarial: o primeiro passo para a promoção da sustentabilidade é apresentar práticas de recursos humanos que reconheçam, estimulem e valorizem ações socioambientais dos funcionários.

Na literatura, a GRH e a gestão ambiental são áreas que têm evoluído, inclusive reconhecendo que o foco exclusivamente sobre o desempenho financeiro representa uma visão limitada, de modo que os enredamentos das organizações em ambientes competitivos exigem novos mode- 
los que criem interdependências entre os vários elementos que compõem um sistema maior na organização (JACKSON et al., 2011), em que várias áreas se integram em prol de um objetivo comum.

Para tal, a gestão ambiental deve estar fomentada em uma abordagem sistêmica para a integração da temática ambiental em todos os níveis organizacionais (JABBOUR; SANTOS; NAGANO, 2010). Nesse sentido, há uma necessidade crescente para a integração da gestão ambiental com as práticas de recursos humanos (DUTTA, 2012). Essa integração com a área de recursos humanos denomina-se Green Human Resource Management (GHRM) (RENWICK; REDMAN; MAGUIRE, 2008; JACKSON et al., 2011), Greening people (WEHRMEYER, 1996), Greening of human resources (MADSEN; ULHOI, 2001) ou Green (Environmental) Human Resource Management (RENWICK et al., 2012), apresentando-se como uma nova abordagem que explicita como as práticas de recursos humanos podem contribuir para um desempenho ambiental empresarial superior (MULLER-CARMEN et al., 2010).

Dentre as várias denominações, este artigo utilizará a nomenclatura gestão de recursos humanos verde (GRHV), que consiste no desenvolvimento de critérios ambientais para as práticas e políticas de recursos humanos, fomentando uma cultura organizacional ambiental que contribua para a redução do uso de recursos naturais e matérias-primas e, consequentemente, reduza os impactos ambientais.

\subsection{Práticas de gestão de recursos humanos verde}

Uma das estratégias para criar uma cultura organizacional voltada ao meio ambiente é recrutar e selecionar candidatos comprometidos com as questões ambientais. Nessa conjectura, a prática de recrutamento e seleção baseada em critérios ambientais pode criar e manter uma organização proativa do ponto de vista ambiental por meio da contratação de funcionários que estejam dispostos a se envolver com as atividades de gestão ambiental (RENWICK; REDMAN; MAGUIRE, 2013).

Para recrutar pessoas com valores ambientais, as empresas podem, por exemplo, mostrar seus programas e suas políticas ambientais em feiras de emprego, oferecer aos funcionários dias de folga para trabalharem como voluntários na comunidade, organizar equipes focadas na reciclagem etc. (LIEBOWTZ, 2010).

A esse respeito, Jabbour, Santos e Nagano (2009) asseveram que selecionar pessoas comprometidas com o meio ambiente facilita a sensibilização de novos funcionários para com as questões de gestão ambiental. Para Renwick, Redman e Maguire (2013), uma organização proativa ambientalmente exige que a organização contrate funcionários dispostos a se envolver com atividades de gestão ambiental. A prática de recrutamento ambiental assegura que a empresa recrute candidatos envolvidos com uma cultura ambiental (MANDIP, 2012).

Dentre as práticas de GRHV, a de treinamento é considerada essencial para a gestão ambiental (JABBOUR; TEIXEIRA; JABBOUR, 2012), consistindo em um fator crítico para a melhoria da gestão ambiental nas organizações (PERRON; COTE; DUFFY, 2006), pois possibilita o aumento de conhecimentos, habilidades, sensibilização e conscientização acerca das questões ambientais (TEIXEIRA, 2010), transmitindo mais segurança aos funcionários quanto à capacidade para realizar seu trabalho (GRUMAN; SAKS, 2011).

O treinamento ambiental, segundo Jabbour, Santos e Nagano (2009), deve ser aplicado a todos os funcionários da organização, inclusive aos terceirizados, com ênfase nos aspectos ambientais inerentes a cada cargo, proporcionando informações sobre a política ambiental da empresa, suas práticas e as atitudes necessárias para realizá-la.

Os funcionários devem estar bem-informados sobre questões ambientais que afetam o 
seu local de trabalho (MADSEN; ULHOI, 2001). Conforme a ISO 14001, a formação e o desenvolvimento ambiental sãoessenciais para a implementação da norma, bem como para o desenvolvimento de uma cultura voltada à conscientização ambiental (DAILY; HUANG, 2001).

Segundo Gruman e Saks (2011), a avaliação de desempenho deve considerar o comprometimento e o desempenho do funcionário no trabalho, além de fornecer feedback, permitindo que gestores e funcionários avaliem o grau de cumprimento das metas de desempenho a partir de um planejamento. Não obstante, a avaliação de desempenho deve ser estruturada por meio de indicadores de desempenho ambiental, das responsabilidades envolvidas, dos feedbacks dos resultados alcançados e do estabelecimento de metas e objetivos (RENWICK; REDMAN; MAGUIRE, 2008), incluindo, por exemplo, fatores como conhecimento dos regulamentos ambientais, responsabilidades pelas decisões com potencial ambiental e consequências ambientais (JACKSON; SCHULER; JIANG, 2014).

A avaliação do desempenho ambiental fornece um feedback sobre o desempenho ambiental do funcionário para fins de inibição de comportamentos não desejados ou reforço de comportamentos positivos (JABBOUR; SANTOS; NAGANO, 2009), devendo cumprir os critérios de confiabilidade, validade e justiça, fornecendo feedback útil aos funcionários e apoiando a melhoria contínua dos resultados ambientais (JACKSON et al., 2011).

A ligação entre o sistema de recompensas e a gestão ambiental, contudo, raramente é mostrada na literatura (RENWICK; REDMAN; MAGUIRE, 2013), apesar de desempenhar um papel importante no alcance das metas e dos objetivos ambientais, estimulando as pessoas com bônus financeiro e outras formas de recompensa (JACKSON; SCHULER; JIANG, 2014).

A prática de recompensas baseada em critérios ambientais pode trazer benefícios à gestão ambiental (MASSOUD; DAILY; BISHOP, 2008), especialmente se os sistemas de recompensas forem estruturados visando às performances ambientais (DUTTA, 2012). Nessa ótica, a área de recursos humanos pode desenvolver programas de recompensa para equipes inovadoras que promovam ideias que contribuam para a redução do uso dos recursos naturais (LIEBOWTZ, 2010), por meio do estabelecimento de recompensas financeiras e não financeiras, que são ferramentas potencialmente poderosas para apoiar as atividades de gestão ambiental (JACKSON et al., 2011).

As recompensas fundamentadas emcritérios ambientais podem estimular os funcionários a incorporarem as questões ambientais no seu cotidiano e atingir os objetivos ambientais desejados pela empresa (JABBOUR; SANTOS; NAGANO, 2009; JACKSON; SCHULER; JIANG, 2014), aumentando seu comprometimento com as questões ambientais (DAILY; HUANG, 2001).

\subsection{Caracterização do setor metalomecânico no brasil}

O setor metalomecânico compreende a metalurgia, a fabricação de produtos de metal, de máquinas e equipamentos, de automóveis e de outros produtos de transporte (SENAI, 2008), sendo responsável pela geração e difusão de novas tecnologias para os demais setores industriais (SEBRAE, 2010) e considerado a base para outros setores industriais (OENNING JUNIOR, 2006).

O setor metalomecânico faturou R\$ 81,2 bilhões em 2011, representando 2,7\% do Produto Interno Bruto (PIB) nacional. Foi responsável por US\$11,9 bilhões das exportações brasileiras, especialmente para a América Latina (41,4\%), a Europa (17,1\%) e os Estados Unidos (20\%) (Anuário 2011-2012/ABIMAQ), correspondendo a 35,2\% do PIB da indústria nacional (FIERGS, 2011).

Segundo a CNI/ABIMAQ (2012), a Associação Brasileira de Máquinas e Equipamentos (ABIMAQ) representa $33 \%$ do setor, reunindo 1.500 empresas associadas dentro de um universo de 4.500 empresas, das quais $60 \%$ são consideradas pequenas empresas (faturamento anual até R\$ 10,5 milhões), $30 \%$ são consideradas médias empresas e $10 \%$ são tidas como grandes empresas 
(faturamento até R\$ 60 milhões). Para a Federação das Indústrias do Rio Grande do Sul (FIERGS, 2011), as empresas de micro e pequeno porte representam $95,5 \%$ do total da economia brasileira.

\section{PROCEDIMENTOS METODOLÓGICOS}

Para atingir o objetivo deste estudo, realizou-se uma pesquisa quantitativa, por meio de um survey, visando testar o modelo proposto (Figura 1), construído a partir do referencial teórico, em que foram identificadas as práticas funcionais de recursos humanos, recrutamento e seleção (GRHV_5), treinamento (GRHV_6), avaliação de desempenho (GRHV_7) e recompensas (GRHV_8) como as mais citadas pelos autores que pesquisaram a gestão de recursos humanos verde (GRHV) e os aspectos ambientais significativos que se relacionam com o desempenho ambiental (DA) - matéria-prima (DA_9), energia (DA_10 e DA_11), água (DA_12), efluentes (DA_13), emissões atmosféricas (DA_14 e DA_15) e resíduos sólidos (DA_16 e DA_17) -, conforme definição da norma ISO 14031/2004.

A relação entre os construtos propostos (GRHV e DA) está diretamente relacionada aos objetivos e pretende responder à seguinte hipótese $(\mathrm{H} 1)$ : "as empresas do setor metalomecânico desenvolvem práticas de recursos humanos ambientais que contribuem para melhoria do desempenho ambiental".

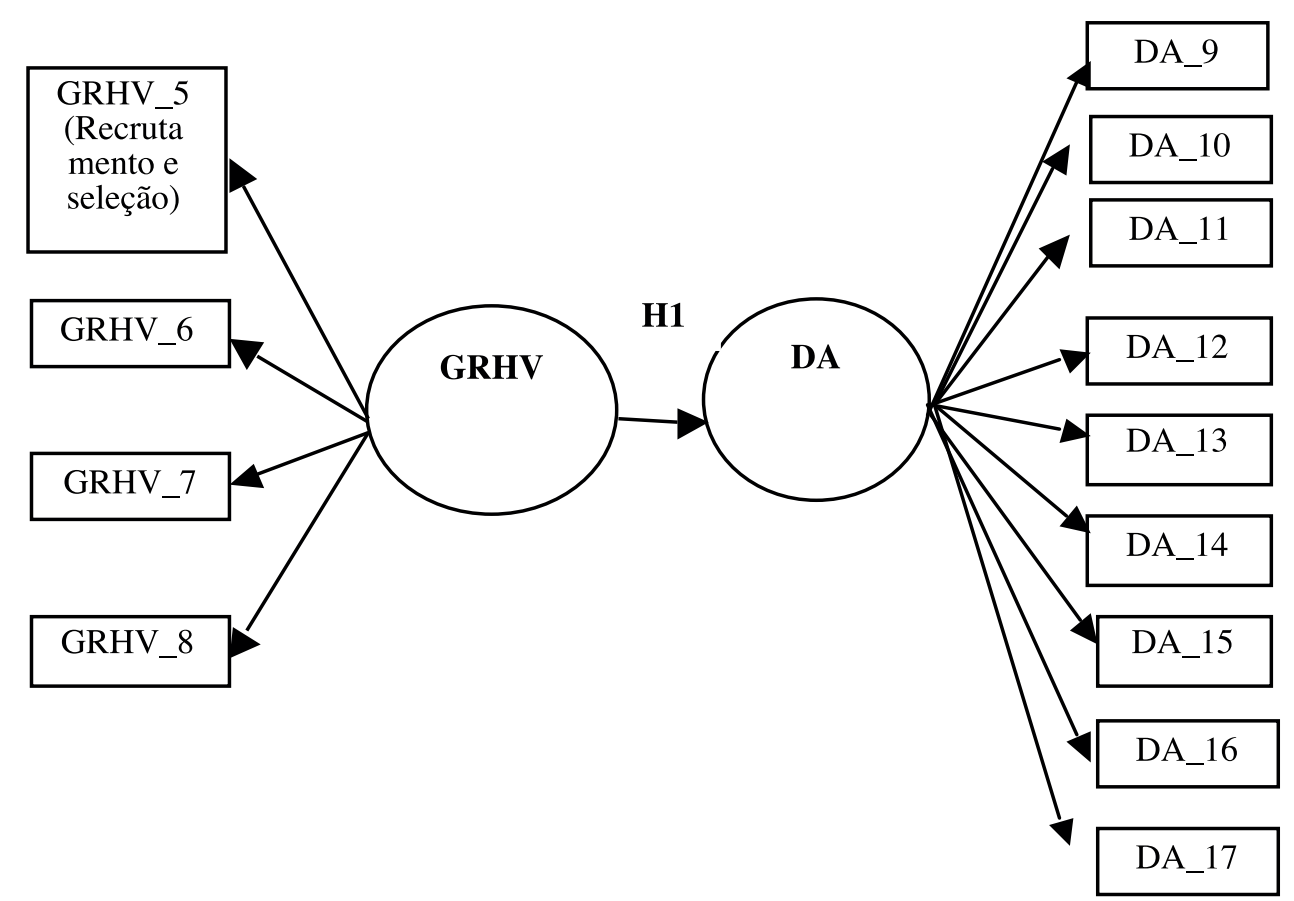

Figura 1: Diagrama de caminho das relações causais entre as variáveis Fonte: elaborado pelos autores

Após a elaboração do instrumento de coleta de dados, realizou-se um pré-teste entre 10 e 20 de março de 2014, com a finalidade de aprimorar o questionário quanto à forma e ao conteúdo. Dez empresas do setor metalomecânico foram convidadas a participar do pré-teste, mas apenas cinco empresas aceitaram o convite, além de dois pesquisadores com expertise no tema para avaliar o questionário, com vistas a auxiliar a refinar os procedimentos e instrumentos para coleta de dados (SYNODINOS, 2003). Após a validação do questionário, o passo seguinte consistiu 
na elaboração da versão final do instrumento para a coleta de dados. A escala adotada teve cinco pontos variando entre extremos " 1 - discordo totalmente" e " 5 - concordo totalmente".

O questionário foi autoadministrado, considerado o mais recomendado para pesquisas com o método survey (SYNODINOS, 2003), e construído sob a plataforma da web, com a ferramenta Survey monkey, o que aumentou a agilidade no processo de coleta de dados.

A população em estudo foi composta das 1.410 empresas do setor mecânico da Associação Brasileira da Indústria de Máquinas e Equipamentos (ABIMAQ), conforme informado no site da associação em 13 de janeiro de 2013.

Os respondentes-chave são os gestores de produção, pois a produção/operação é responsável pela maior parte dos impactos ambientais em razão dos recursos de processos, tendo efeitos ambientais significativos. Além disso, os gestores de produção são gerentes de linha que aplicam as práticas de recursos humanos na gerência dos funcionários na área de fabricação (JABBOUR et al., 2013) e/ou gerentes gerais e/ou responsáveis pela empresa, desde que possuam amplo conhecimento sobre a gestão da empresa como um todo.

Para o cálculo da amostra, foi utilizado o software gratuito G*Power 3.1.9.2 (FAUL et al., 2009). Os parâmetros técnicos utilizados no software foram: família ( $F$ tests), tipo de teste estatístico (Linear multiple regression: Fixed model, $R^{2}$ deviation from zero) e tipo de análise (a priori: compute required sample size - given, power, and effect size), tamanho do efeito, 0,15, nível de significância erro permitido de 0,05, com nível de significância de 95\%, poder estatístico 0,80, com apenas 1 preditor, conforme exemplo de Ringle, Silva e Bido (2014). Assim, o teste determinou uma amostra mínima de 55 questionários, tendo sido utilizados no total, 108 questionários válidos, quase o dobro do recomendado, correspondendo a uma taxa de retorno de 7,65\%.

Com um efetivo funcional de mais de 260 mil pessoas (outubro de 2012) (Anuário 2011-2012/ ABIMAQ), 90\% das empresas do setor adotam políticas que visam reduzir o impacto ambiental (CNI/ $A B I M A Q, 2012)$, evidenciando a importância da identificação da GRHV no setor metalomecânico.

A primeira remessa de questionários enviados, que ocorreu por meio do envio do link do questionário (https://pt.surveymonkey.com/s/rh_verde) por e-mail, para as 1.410 empresas ocorreu no dia 5 de junho de 2014. Foram realizadas mais duas remessas, finalizando a coleta de dados em 1 ㅇ de julho de 2014. Ao todo, obtiveram-se 108 questionários válidos, o que corresponde a uma taxa de retorno de $7,65 \%$.

As análises dos dados coletados nos questionários foram realizadas via estimação Partial Least Squares ou Mínimos Quadrados Parciais (PLS), a fim de verificar relações complexas entre variáveis latentes (HENSELER; SARSTEDT, 2013). Para Jabbour et al. (2013), a PLS é útil especialmente quando se trata de teoria complexa e estágios iniciais de desenvolvimento, além de ser adequada para amostras consideradas pequenas (LATAN; RAMLIDAQUI, 2013; HENSERLER; RINGLE; SINKOVICS, 2009; HAIR; HINGLE; SARSTEDT, 2011).

Operacionalmente, os seguintes testes estatísticos foram realizados, com base nas recomendações propostas por Ringle, Silva e Bido (2014): Variâncias Médias Extraídas (AVE), Cargas Cruzadas, Critério de Fornell e Larcker, Alfa de Cronbach e Confiabilidade composta, Teste t de Student, Avaliação dos coeficientes de Determinação de Pearson $\left(R^{2}\right)$, Tamanho do efeito $\left(\mathrm{f}^{2}\right)$ ou indicador de Cohen, Validade preditiva $\left(\mathrm{Q}^{2}\right)$ ou indicador de Stone-Geisser, GoF e Coeficiente de Caminho. Para operacionalizar a análise dos dados, dois softwares foram utilizados: Excel e Software Smart PLS. Por fim, a análise final consistiu na comparação e discussão dos dados com o referencial teórico que embasa este estudo. 


\section{DESCRIÇÃO DOS RESULTADOS QUANTITATIVOS}

A Partial Least Squares (PLS) tem dois componentes: o modelo estrutural e o modelo de mensuração (TENENHAUS et al., 2005; HENSERLER; RINGLE; SINKOVICS, 2009; HAIR; HINGLE; SARSTEDT, 2011). O modelo estrutural indica as relações de dependência conectando os construtos previstos no modelo, e o modelo de mensuração "especifica os indicadores para cada construto e viabiliza a avaliação da validade de construto (HAIR et al., 2009, p. 542).

\subsection{Modelo de mensuração}

Seguindo as recomendações de Ringle, Silva e Bido (2014), o primeiro aspecto a ser observado no modelo de mensuração (Figura 2) são as validades convergentes, obtidas por meio das Variâncias Médias Extraídas (AVE). A validade convergente avalia o quanto duas medidas do mesmo conceito estão correlacionadas (HAIR JR. et al., 2009)

Dessa maneira, uma AVE superior a 0,50 indica o ajustamento e a confiabilidade do modelo (HAIR; HINGLE; SARSTEDT, 2011).

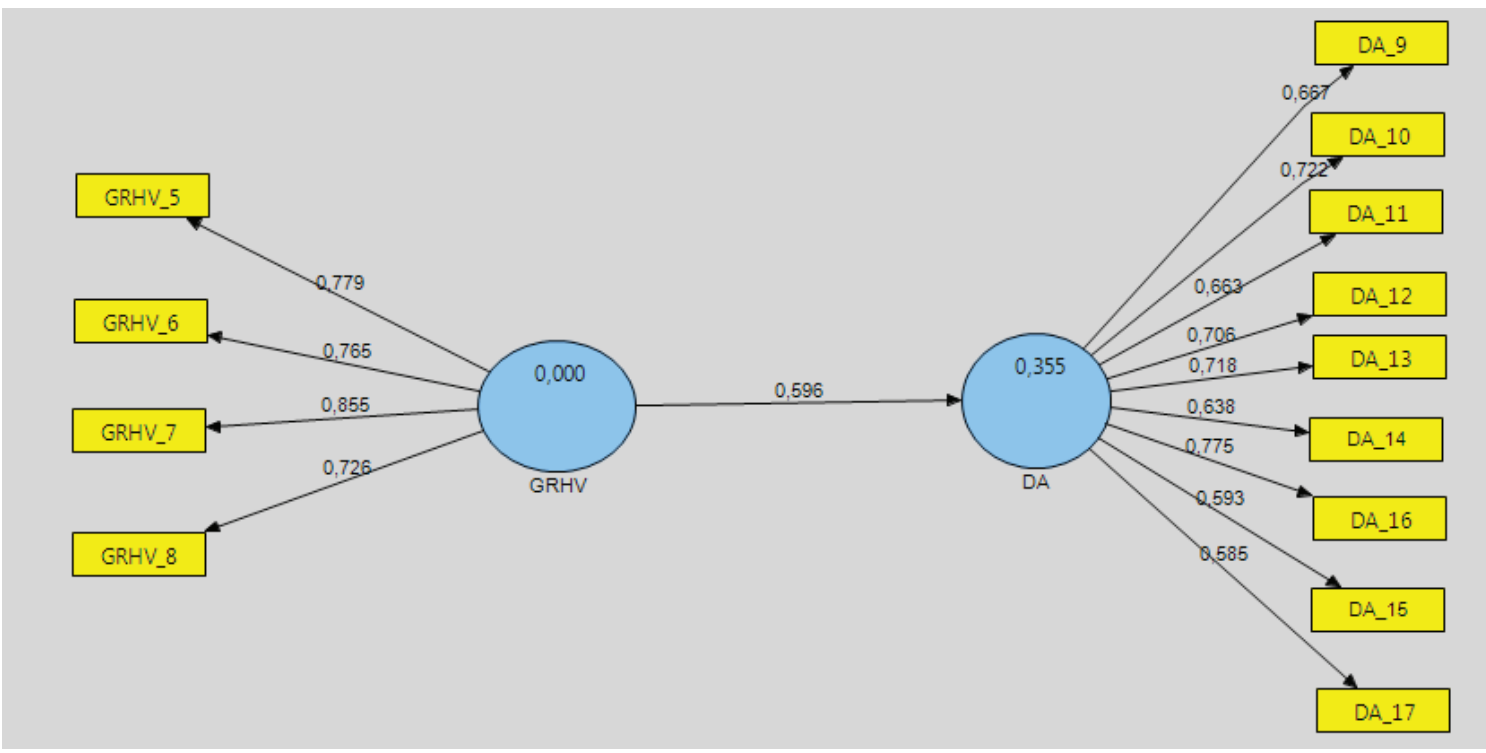

Figura 2: Modelo de Mensuração - relação entre GRHV e DA

Fonte: gerado automaticamente pelo SMART PLS $2.0 \mathrm{M} 3$

Nota1: Factor Weighting Scheme; Mean 0, Var. 1; Max. Iteration 300

A Tabela 1, exposta a seguir, indica que há confiabilidade composta nos dados do construto desempenho ambiental (DA) $(0,882967)$ e gestão de recursos humanos verde (GRHV) $(0,863140)$. Contudo, apenas o construto GRHV apresentou a validade convergente, pois o construto DA apresentou índices abaixo dos valores recomendados para AVE $(0,457921)$. Assim, o modelo não converge a um resultado satisfatório. 
Tabela 1: Valores da qualidade de ajuste do modelo

\begin{tabular}{ccccc}
\hline Construto & AVE & $\begin{array}{c}\text { Confiabilidade } \\
\text { Composta }\end{array}$ & $\mathbf{R}^{2}$ & Alpha de Cronbachs \\
\hline Desempenho Ambiental & 0,457 & 0,882 & 0,355 & 0,851 \\
\hline $\begin{array}{c}\text { Gestão de Recursos Humanos } \\
\text { Verde }\end{array}$ & 0,612 & 0,863 & - & 0,788 \\
\hline
\end{tabular}

Fonte: dados da pesquisa

Nota: o construto GRHV não tem $\mathrm{R}^{2}$, pois é independente e antecessor do Desempenho Ambiental.

Nos casos em que os índices de AVE se apresentam menores que 0,50, Latan e Ramlidaqui (2013) e Ringle, Silva e Bido (2014) recomendam que as variáveis mensuradas devem ser eliminadas com a finalidade de elevar o valor da AVE. Logo, procedeu-se à eliminação das variáveis "Q14 - Nossa empresa reduziu a emissão de poluição atmosférica" e "Q15 - Realizamos inventário das emissões atmosféricas", visando obter um melhor ajustamento e confiabilidade do modelo (Figura 3).

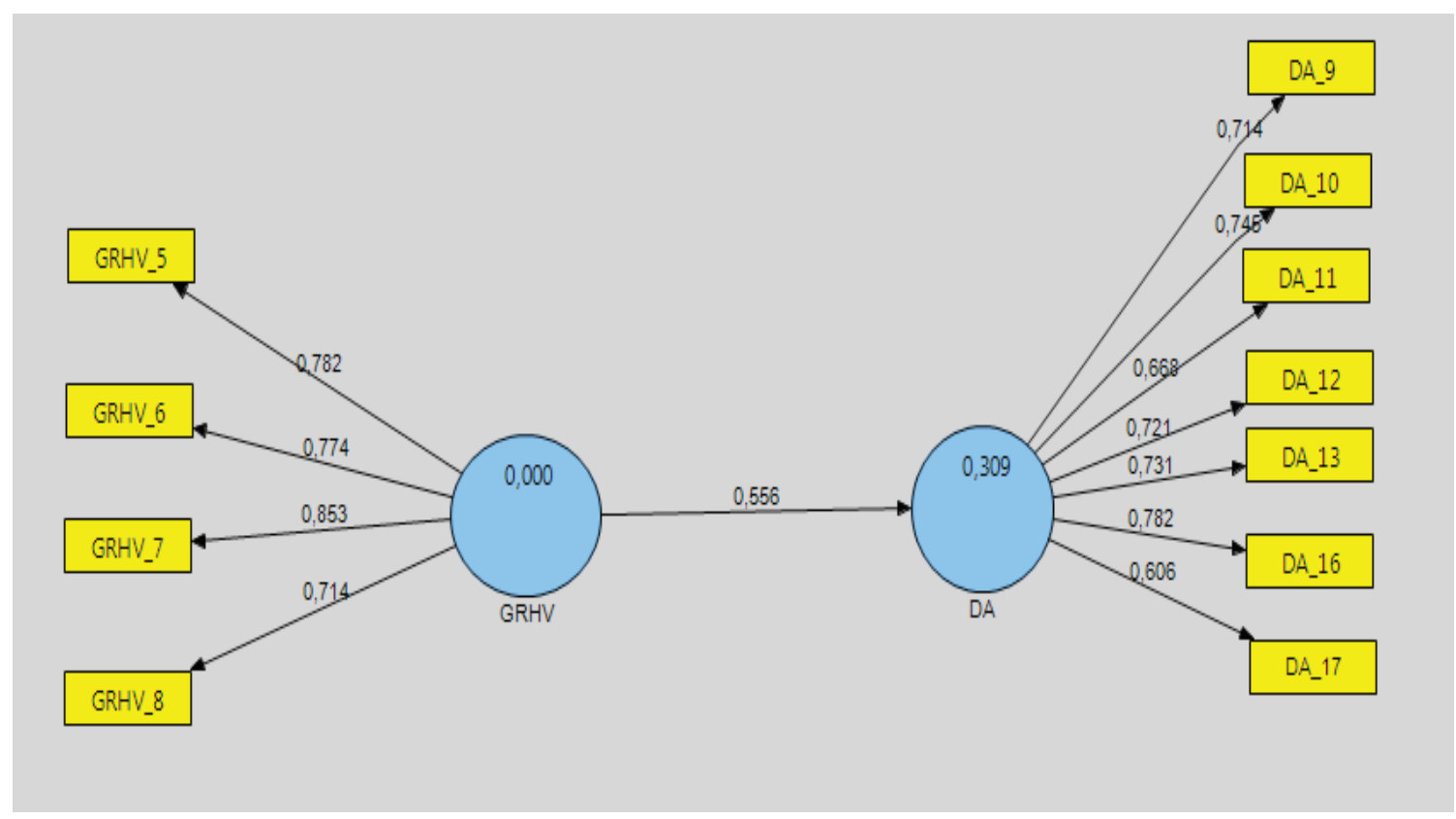

Figura 3 - Resultado do modelo de mensuração após a exclusão das variáveis Q14 e Q15 Fonte: gerado automaticamente pelo SMART PLS 2.0 M3

A Tabela 2 demonstra que, após a exclusão da variável Q14 e Q15, o modelo apresentou validade convergente, pois a AVE, tanto de DA quanto de GRHV, apresentou índices maiores que o recomendado $(0,50)$ e confiabilidade composta $>$ que 0,70 .

Tabela 2: Valores da qualidade de ajuste do modelo após exclusão de variáveis

\begin{tabular}{c|c|c|c|c}
\hline Construto & AVE & $\begin{array}{c}\text { Confiabilidade } \\
\text { Composta }\end{array}$ & R Square & Alpha de Cronbachs \\
\hline Desempenho Ambiental & 0,506 & 0,877 & 0,309 & 0,837 \\
\hline $\begin{array}{c}\text { Gestão de Recursos Humanos } \\
\text { Verde }\end{array}$ & 0,613 & 0,862 & - & 0,788 \\
\hline
\end{tabular}

Fonte: dados da pesquisa

Nota: o construto GRHV não tem $\mathrm{R}^{2}$, pois é independente e antecessor do Desempenho Ambiental. 
Para demonstrar a confiabilidade do modelo, avalia-se a consistência interna e a confiabilidade composta, que é a segunda etapa da PLS (HINGLE; BIDO; SILVA, 2014). A consistência interna é medida pelo Alfa de Cronbach (AC) com valores variando entre 0 e 1,0, (HAIR JR. et al., 2009), ressaltando-se que valores acima de 0,6 podem ser satisfatórios para a coerência interna (MALHOTRA, 2012), o que indica a confiabilidade da escala. Já a confiabilidade composta (CC), de acordo com Hair Jr. et al. (2009), é a medida mais recomendada no contexto de equações estruturais e deve ser maior que 0,7 .

Os valores da Tabela 2 demonstram que, tanto para o construto DA (AC 0,837 e CC 0,877 ) quanto para o construto GRHV (AC 0,788 e CC 0,862), houve confiabilidade do modelo.

A terceira fase consiste na avaliação da validade discriminante. Segundo Ringle, Silva e Bido (2014), há duas maneiras para avaliar a validade discriminante: por meio das cargas cruzadas (crossloading) e pelo critério de Fornell e Larcker (1981). Na Tabela 3, a seguir, constatou-se nas cargas cruzadas que os construtos diferem dos demais (HAIR et al. 2009), pois as cargas são maiores nos seus indicadores do que nos outros indicadores do outro construto.

Tabela 3: Valores das cargas cruzadas de DA e GRH

\begin{tabular}{c|c|c}
\hline Variável & DA & GRHV \\
\hline GRHV_5 & 0,435 & 0,781 \\
\hline GRHV_6 & 0,487 & 0,773 \\
\hline GRHV_7 & 0,461 & 0,853 \\
\hline GRHV_8 & 0,328 & 0,713 \\
\hline DA_9 & 0,714 & 0,439 \\
\hline DA_10 & 0,745 & 0,386 \\
\hline DA_11 & 0,667 & 0,466 \\
\hline DA_12 & 0,721 & 0,333 \\
\hline DA_13 & 0,731 & 0,340 \\
\hline DA_16 & 0,782 & 0,440 \\
\hline DA_17 & 0,606 & 0,303 \\
\hline
\end{tabular}

Fonte: dados da pesquisa

Outra forma para avaliar a validade discriminante é o critério de Fornell e Larcker (1981). Com base nesse teste, constatou-se que os valores das raízes quadradas são maiores que os respectivos construtos ou variáveis latentes (Tabela 4), isto é, o valor da raiz quadrada tanto de DA $(0,711)$ e GRHV $(0,783)$ é maior que 0,554 , sendo a correlação entre os construtos.

Tabela 4: Correlações entre os construtos e raízes da AVE

\begin{tabular}{c|c|c}
\hline & DA & GRHV \\
\hline DA & $\mathbf{0 , 7 1 1}$ & - \\
\hline GRHV & 0,554 & $\mathbf{0 , 7 8 3}$ \\
\hline
\end{tabular}

Fonte: dados da pesquisa

Dessa maneira, o modelo de mensuração foi finalizado com os testes, sendo aprovado.

\subsection{Modelo estrutural}

A primeira análise do modelo estrutural foi a avaliação dos Coeficientes de Determinação de Pearson $\left(R^{2}\right)$, que avaliam parte da variância das variáveis dependentes explicadas pelo modelo estrutural (HINGLE; SILVA; BIDO, 2014). Logo, obteve-se um $R^{2}$ de 0,309, indicando a qualidade do modelo ajustado, tendo um grande efeito (COHEN, 1988) na dimensão ambiental. 
O nível de significância do modelo foi avaliado pela técnica de Bootstrapping. Esse método, segundo Hair et al. (2009), permite ao pesquisador não se preocupar com a duplicação dos dados, exceto quando ocorrer ao acaso. Foram realizadas 1000 reamostragens em 108 casos, com a opção "Individual Changes" recomendada por Henseler ET al. (2009). Um resultado igual ou superior a 1,96, obtido pelo teste $t$ de Student (HAIR et al., 2009; RINGLE; SILVA; BIDO, 2014) é considerado aceitável. Obteve-se um resultado de 9,915, superior ao recomendado, confirmando a hipótese estabelecida, isto é, de que as práticas de recursos humanos influenciam o desempenho ambiental das empresas do setor metalomecânico (Figura 4).

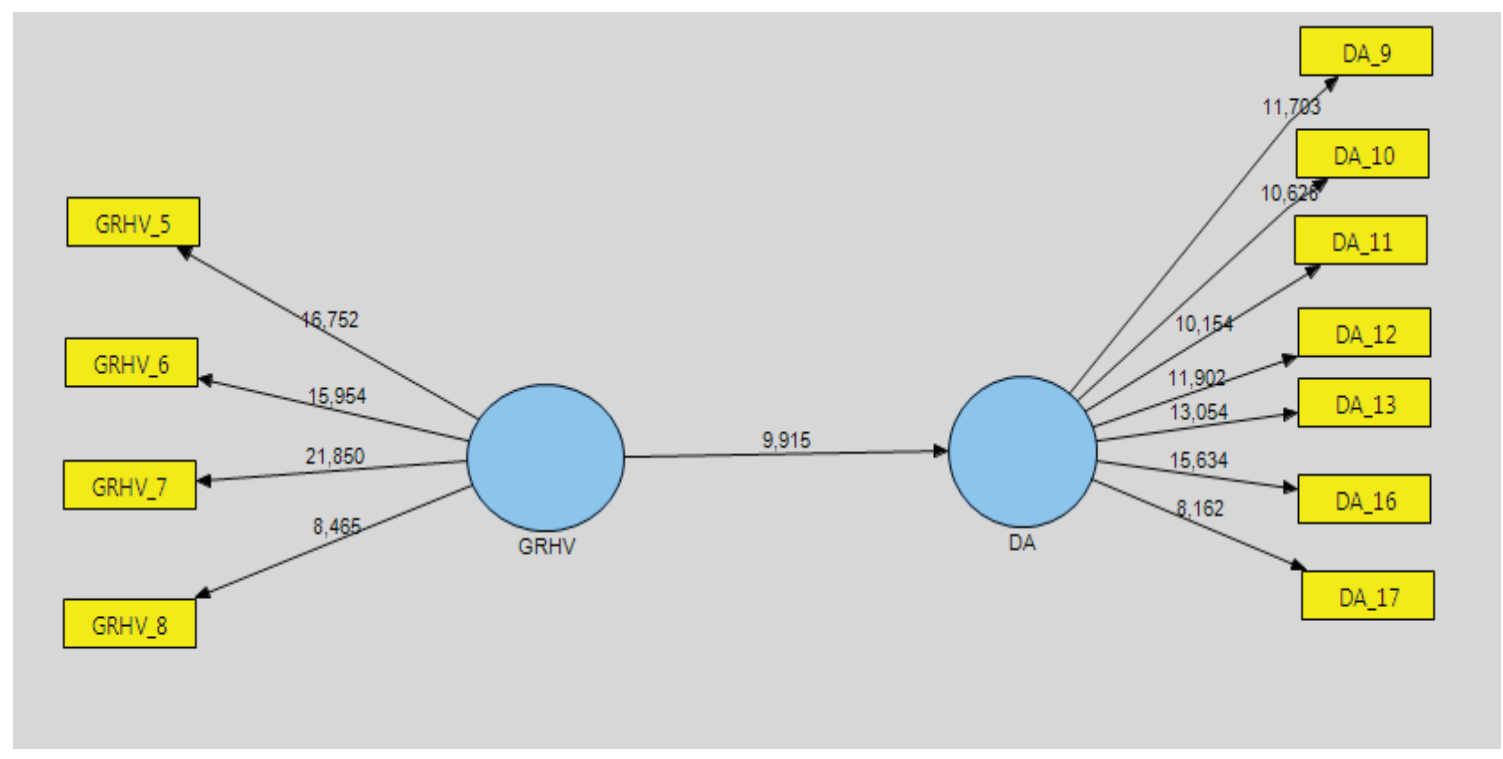

Figura 4: Testet de Student obtidos com o Bootstrapping do Smart PLS

Fonte: gerado automaticamente pelo SMART PLS2.0 M3

Nota 1: Bootstrapping -> Sign Changes = Individual Changes; Cases 108 Sample 2000

Por fim, a Tabela 5 apresenta as cargas fatoriais da amostra, a média amostral,o desvio padrão da amostra, seu erro padrão e o "valor $t$ estatístico", apresentando um índice $t$ muito superior ao recomendado pela literatura.

Tabela 5: Parâmetros do Bottstraping

\begin{tabular}{c|c|c|c|c|c}
\hline \multirow{2}{*}{ GRHV à DA } & $\begin{array}{c}\text { Amostra } \\
\text { original }\end{array}$ & $\begin{array}{c}\text { Amostra } \\
\text { média }\end{array}$ & $\begin{array}{c}\text { Desvio } \\
\text { padrão }\end{array}$ & $\begin{array}{c}\text { Erro pa- } \\
\text { drão }\end{array}$ & Teste $\boldsymbol{t}$ \\
\cline { 2 - 7 } & 0,555 & 0,575 & 0,056 & 0,056 & 9,915 \\
\hline
\end{tabular}

Fonte: dados da pesquisa

Outros dois indicadores de qualidade de ajuste do modelo foram avaliados: relevância ou validade preditiva $\left(\mathrm{Q}^{2}\right)$ e tamanho do efeito $\left(\mathrm{f}^{2}\right)$. $\mathrm{O} \mathrm{Q}^{2}$ avalia a precisão do modelo ajustado, e o $f^{2}$ avalia quanto cada construto é "útil" para o ajuste do modelo (RINGLE; SILVA; BIDO, 2014) (vide Tabela 6). Obteve-se $Q^{2}$ maior que zero, tanto para o construto DA quanto para o GRHV, e f ${ }^{2}$ com valores próximos à dimensão grande, indicando que o modelo tem acurácia e que os constructos são relevantes para o ajuste do modelo. 
Tabela 6: Valores de indicadores de validade preditiva $\left(\mathrm{Q}^{2}\right)$ e tamanho do efeito $\left(\mathrm{f}^{2}\right)$

\begin{tabular}{|c|c|c|}
\hline Constructos & CV RED $\left(\mathbf{Q}^{2}\right)$ & CV $\operatorname{COM}\left(f^{2}\right)$ \\
\hline DA & 0,140 & 0,337 \\
\hline GRHV & 0,351 & 0,351 \\
\hline Valores referenciais & $\mathrm{Q}^{2}>0$ & $\begin{array}{c}0,02,0,15 \text { e } 0,35 \text { para pequenos, médios e gran- } \\
\text { des }\end{array}$ \\
\hline
\end{tabular}

Fonte: dados da pesquisa, obtido pelo relatório Blindfolding no Smart PLS.

Ressalta-se, ainda, que Ringle, Silva e Bido (2014) recomendam a avaliação dos indicadores de ajuste geral do modelo por meio dos índices obtidos pelo GoF. Wetzels, Odekerken-Schröder e Oppen (2009) afirmam que índices de 0,10, 0,25 e 0,36 representam, respectivamente, um ajuste pequeno, médio e grande do modelo.

Assim, utiliza-se a fórmula GoF = VAAVE x AARS, na qual AAVE é a média das AVE e a AARS é a média do $R^{2}$ ajustado. Destaca-se que o Smart PLS 2.0 M3 não realiza esse cálculo.

$O R^{2}$ ajustado é calculado pela Equação (1), em que $R^{2}$ corresponde ao R-Quadrado, $n$ ao tamanho da amostra e $k$ ao número de variáveis preditoras, obtendo-se o valor 0,30248 de $\mathrm{R}^{2}$ ajustado:

$$
R_{Y}^{2}=1-\left(1-R_{Y}^{2}\right) \frac{n-1}{n-k-1}
$$

Equação (1)

Consequentemente, obteve-se a AAVE = média da AVE =0,5595 e AARS = média do $\mathrm{R}^{2}$ ajustado 0,30248. $O$ valor de GoF é 0,411 , sendo considerado um ajuste grande para o modelo.

Após realizar todos os testes, interpretaram-se os coeficientes obtidos à luz da teoria que fundamenta esta pesquisa.

\section{ANÁLISE E DISCUSSÃO DOS RESULTADOS}

Nesta seção, são discutidos os dados apresentados na seção 4 à luz do refrencial teórico associado. Com base nos resultados quantitativos, em que o modelo foi testado por meio do software Smart PLS, junto a uma amostra do setor metalomêcanico composta de 108 empresas, pode-se afirmar que as práticas de recursos humanos verdes colaboram para o desempenho ambiental no, confirmando a hipótese de pesquisa (H1). Os resultados vão ao encontro do que preveem Jabbour et al. (2012), ao identificarem que as práticas de recrutamento e seleção, treinamento, avaliação de desempenho e recompensas relacionam-se positivamente com práticas de gestão ambiental no setor automotivo brasileiro.

Em relação à descrição das organizações na fase quantitativa, que se refere à caracterização das empresas participantes da amostra, mais de $90 \%$ estão localizadas nas regiões Sul e Sudeste, resultado semelhante ao constatado na pesquisa de Souza, Moori e Marcondes(2004).

Verificou-se, ainda, que $70,05 \%$ da amostra é composta de micro e pequenas empresas. Apesar de serem consideradas pequenas, apresentam uma gestão ambiental efetiva em relação aos recursos naturais e ao consumo de matéria-prima. Tal fato pode ser explicado pela própria especificidade do setor estudado, que é considerado como de médio a alto impacto ambiental pela legislação brasileira (Lei n. 10.165/2000).

As empresas pesquisadas neste estudodesenvolvem o recrutamento, a seleção, o treinamento, a avaliação de desempenho e as recompensaslevando em conta algum critério ambiental que se relaciona positivamente com a redução no consumo de matéria-prima, de água e energia e com a gestão dos efluentes residuais e dos resíduos sólidos. 
Em relação à certificação ambiental, apenas $8,4 \%$ das empresas do setor metalomêcanico que compõem a amostra apresentaram a certificação, resultado próximo ao da pesquisa realizada pela Confederação Nacional da Indústria (CNI/ABIMAQ, 2012), quando constatou que 12,96\% das empresas associadas junto à Associação Brasileira de Máquinas e Equipamentos (ABIMAQ) apresentavam a certificação ISO 14001/2002.

Dessa forma, ações ambientais irresponsáveis, como despejo de efluentes sem tratamento em rios, destinação de resíduos para locais não apropriados e desperdício de água, implicariam multas, protestos sociais e reflexos negativos na imagem organizacional. Logo, tanto uma pequena quanto uma grande empresa do setor metalomêcanico precisa atuar em relação às questões ambientais, pois seus processos têm uma relação direta com os aspectos e impactos ambientais significativos junto ao meio ambiente.

Para que o modelo conceitual fosse considerado adequado, em termos de validade, confiabilidade, significância e capacidades explicativas, realizaram-se os testes descritos, a seguir, na Tabela 7.

A validade convergente avalia a correlação de duas medidas em um mesmo construto, obtida pela Variância Média Extraída (AVE). Constatou-se que os constructos de gestão de recursos humanos verde (GRHV) e desempenho ambiental (DA) estão acima de 0,50.

A validade discriminante foi obtida pelas cargas cruzadas, pois as cargas são maiores nos seus indicadores do que nos indicadores do outro construto (Tabela 3). Outra forma de obter a validade discriminante é pelo critério de Fornell e Larcker, no qual o valor da raiz quadrada DA $(0,711)$ e GRHV $(0,783)$ é maior que 0,554 , que é a correlação entre os constructos.

A confiabilidade e consistência interna no modelo foram obtidas por duas técnicas. A primeira é o Alfa de Crobach, que deve ser $>0,60$ (MALHOTRA, 2012), tendo sido obtida para o construto DA a carga de 0,837 e para o construto GRHV de 0,788. A segunda técnica consiste na confiabilidade composta,que deve ser $>0,70$ (FORNELL; LARCKER (1981). Para o construto DA, obteve-se um índice de 0,877 e, para o construto GRHV,de 0,862.0 nível de significância das relações do modelo foi obtido pelo Teste $t$,aplicado pela opção Bootstrapping. Obteve-se um resultado de 9,915, superior ao índice de 1,96, que é considerado aceitável (HAIR et al., 2009; RINGLE; SILVA; BIDO, 2014).

Tabela 7: Técnicas utilizadas na PLS

\begin{tabular}{|c|c|c|c|}
\hline Critérios & Técnicas & Valores recomendados & Resultados \\
\hline \multirow{2}{*}{ Validade convergente } & AVE (DA) & \multirow{2}{*}{$\begin{array}{l}>0,50(\text { HAIR JR. et } \\
\text { al., 2011) }\end{array}$} & 0,506 \\
\hline & AVE (GRHV) & & 0,613 \\
\hline \multirow[b]{2}{*}{ Validade discriminante } & Cargas Cruzadas & $\begin{array}{l}\text { Cargas maiores que seus indi- } \\
\text { cadores dos outros contrutos } \\
\text { (HAIR et al., 2009) }\end{array}$ & Atendido \\
\hline & Critério de Fornell e Larcker & $\begin{array}{l}\text { O valor da raiz quadrada da AVE } \\
\text { é maior que a correlação entre } \\
\text { OS constructos (FORNELL; LAR- } \\
\text { CKER, 1981) }\end{array}$ & Atendido \\
\hline \multirow{4}{*}{$\begin{array}{l}\text { Confiabilidade e Consis- } \\
\text { tência interna no modelo }\end{array}$} & Alfa de Cronbach (DA) & \multirow{2}{*}{ >0,60 (MALHOTRA, 2012) } & 0,837 \\
\hline & Alfa de Cronbach (GRHV) & & 0,788 \\
\hline & Confiabilidade composta (DA) & \multirow{2}{*}{$\begin{array}{l}>0,70 \\
1981)\end{array} \quad$ (FORNELL; LARCKER, } & 0,877 \\
\hline & $\begin{array}{l}\text { Confiabilidade composta } \\
\text { (GRHV) }\end{array}$ & & 0,862 \\
\hline Nível de significância & Teste $t$ & $\begin{array}{l}=>1,96 \text { (HAIR et al., 2009; RIN- } \\
\text { GLE; SILVA; BIDO, } 2014\end{array}$ & 9,915 \\
\hline $\begin{array}{l}\text { Capacidades explicativas } \\
\text { do modelo }\end{array}$ & $R^{2}$ & $\begin{array}{l}\text { 0,02 indica efeito pequeno, 0,13 re- } \\
\text { presenta efeito médio e 0,26 apon- } \\
\text { ta grande efeito (COHEN, 1988). }\end{array}$ & 0,309 \\
\hline
\end{tabular}




\begin{tabular}{|c|c|c|c|}
\hline Critérios & Técnicas & Valores recomendados & Resultados \\
\hline \multirow[b]{2}{*}{ Ajuste do modelo } & $f^{2}(D A)$ & \multirow{2}{*}{$\begin{array}{l}\text { 0,02, } 015,0,35 \text { representam efei- } \\
\text { tos, respectivamente, pequeno, } \\
\text { médio e grande (COHEN; 1988; } \\
\text { HENSERLER; RINGLE; SINKOVICS, } \\
\text { 2009) }\end{array}$} & 0,337 \\
\hline & $\mathrm{f}^{2}(\mathrm{GRHV})$ & & 0,351 \\
\hline \multirow{2}{*}{$\begin{array}{l}\text { Qualidade do modelo de } \\
\text { mensuração }\end{array}$} & $Q^{2}(D A)$ & \multirow{2}{*}{$\begin{array}{l}\mathrm{Q}^{2}>0 \quad \text { (HENSERLER; } \\
\text { SINKOVICS, 2009) }\end{array}$} & 0,140 \\
\hline & $\mathrm{Q}^{2}(\mathrm{GRHV})$ & & 0,351 \\
\hline Ajuste global do modelo & GoF & $\begin{array}{l}0,10,0,25 \text { e } 0,36 \text { representam, } \\
\text { respectivamente, um ajuste pe- } \\
\text { queno, médio e grande do mo- } \\
\text { delo (WETZELS; ODEKERKEN-S- } \\
\text { CHRÖDER; OPPEN, 2009). }\end{array}$ & 0,411 \\
\hline
\end{tabular}

As capacidades explicativas do modelo foram obtidas pelo Coeficiente de Determinação de Pearson $\left(R^{2}\right)$, avaliadas pelos indicadores de Cohen (1988): um $R^{2}$ de 0,02 tem um pequeno efeito, de 0,13 tem efeito médio e de 0,26 tem grande efeito. $O$ resultado para $R^{2}$ da amostra foi de 0,309 , indicando um grande efeito no desempenho ambiental.

$\mathrm{O}$ ajuste do modelo foi realizado pela técnica do tamanho do efeito $\left(\mathrm{f}^{2}\right)$, com valores de indicadores de $0,02,015,0,35$,os quais representam efeitos, respectivamente, pequeno, médio e grande (COHEN; 1988; HENSERLER, RINGLE; SINKOVICS, 2009).

O construto DA apresentou um valor de $\mathrm{f}^{2}$ de 0,337 , sendo considerado de grande efeito para o ajustamento do modelo, enquanto o construto GRVH apresentou um valor de $\mathrm{f}^{2}$ de 0,351 , indicando que este construto tem grande efeito para o ajuste do modelo.

Para determinar a qualidade do modelo de mensuração, a técnica utilizada foi a validade preditiva $\left(Q^{2}\right)$, considerando valores referenciais $Q^{2}>0$ (HENSERLER; RINGLE; SINKOVICS, 2009). Para o construto DA, o $Q^{2}$ obtido foi de 0,140, enquanto para o construto GRHV foi de 0,351.

Por fim, para avaliar o ajuste global do modelo, utilizou-se a técnica Goodness of Fit (GoF), com valores referenciais de 0,10, 0,25 e 0,36, representando, respectivamente, um ajuste pequeno, médio e grande do modelo (WETZELS; ODEKERKEN-SCHRÖDER; OPPEN, 2009). O valor obtido de GoF foi de 0,411 , considerado um ajuste grande para o modelo.

Assim, conclui-se queanova abordagem da GRHV contribui efetivamente para o desempenho ambiental (MULLER-CARMEN et al., 2010), refletindo, inclusive, nos aspectos econômicos da organização (MUSTER; SCHRADER, 2011), por meio de redução do consumo de recursos naturais e dos resíduos e efluentes gerados, e respondendo, dessa forma, às lacunas identificadas pelos "call for papers". Logo, verifica-se o "importante papel que é exercido pela atividade industrial para que a sociedade atual possa harmonizar o trinômio: sustentabilidade, meio ambiente e desenvolvimento econômico" (SPERANDIO; GASPAR, 2009, p. 2009), especialmente pela atuação da GRH.

\section{CONSIDERAÇÕES FINAIS}

Os resultados indicaram que, a partir da gestão de recursos humanos verde (GRHV), por meio das práticas como recrutamento e seleção, treinamento, avaliação de desempenho e recompensas, há a influência positiva e significativa sobre a redução do consumo de recursos naturais como água, energia, matéria-prima, bem como redução na geração de resíduos sólidos e efluentes, aspectos ambientais que formam o desempenho ambiental na amostra das empresas do setor metalomecânico. Em outras palavras, a gestão de recursos humanos (GRH) exerce um papel relevante nas empresas que buscam atuar de forma sustentável (BARRETO et al., 2011).

Foram identificados como importantes para o desempenho ambiental os seguintes as- 
pectos: matéria-prima, água, energia, efluentes e resíduos sólidos. 0 aspecto ambiental emissão atmosférica foi excluído do modelo proposto, em razão de apresentar baixa carga fatorial.

Constatou-se, quanto ao estágio da gestão ambiental em empresas do setor metalomecânico, que: (i) 36,12\% da amostra realiza a gestão ambiental a partir da legislação; (ii) 35,18\% desenvolvem a gestão ambiental a partir de um setor específico, focando nos processos produtivos; e (iii) $28,70 \%$ declararam que a adoção de gestão ambiental é vantagem competitiva para o negócio.

Dessa maneira, o modelo proposto de GRHV, o qual foi testado com os dados coletados juntos ao setor metalomecânico, vai ao encontro das recomendações da academia sobre o avanço na teoria Green Human Resource Management. O modelo conceitual proposto foi testado empiricamente junto a uma amostra de 108 empresas vinculadas à Associação Brasileira de Máquinas e Equipamentos (ABIMAQ) e, após a realização de ajustes, demonstrou nível de significância, validade e confiabilidade superior ao recomendado na literatura.

O estudo também contribui para a prática empresarial. Os gestores de recursos humanos da área ambiental e de linha como a área de produção, por exemplo, podem fortalecer a gestão ambiental das empresas formatando a GRH, isto é, desenvolvendo práticas baseadas em critérios ambientais a fim de trazer para as empresas candidatos com consciência e valores ambientais. Assim, a prática de seleção contribuirá e selecionará candidatos que estejam engajados e alinhados com a política ambiental da empresa. Entretanto, não basta somente contratar novos funcionários preocupados com a causa ambiental, pois é preciso que a empresa prepare internamente os funcionários nesse sentido. Logo, o treinamento é uma ferramenta fundamental para a disseminação da cultura ambiental, funcionando como um ajuste das pessoas aos moldes da organização com foco ambiental.

Quanto às recompensas, seria importante que as empresas inserissem formas de remuneração variáveis, juntamente com o modelo de remuneração fixa, alinhadas com as sugestões e os resultados ambientais, vinculadas a um programa de avaliação de desempenho que leva em conta as práticas de treinamento e de contratações e as recompensas destinadas àqueles que demonstram se enquadrar no que é proposto pela organização.

Contudo, o GRHV pode ser desenvolvido a partir de outras perspectivas, como por meio de uma abordagem mais "soft", denominada de "organizações humanamente sustentáveis" (MATOS; QUELHAS, 2008), que é apresentada no intuito de valorizar e satisfazer as pessoas. Outra forma de GRHV consiste na mudança da organização do trabalho, incentivando, por exemplo, redução do uso de papel com a utilização da tecnologia da informação; promoção de incentivos ao trabalho virtual; horários flexibilizados; transporte compartilhado; e uso de transporte público e de bicicletas. Consequentemente, a GRH contribui para a redução dos impactos ambientais por meio do próprio repensar na forma de atuação da área.

Quanto às limitações deste estudo, destaca-se a baixa participação das empresas associadas à $A B I M A Q$, o que refletiu no baixo índice de retorno, apesar de ser estatisticamente relevante e suficiente para o processamento no Smart PLS. Além disso, como a pesquisa tem fins exploratórios, os resultados correspondem apenas à amostra selecionada, não sendo possível sua generalização para a população como um todo.

Como sugestões para pesquisas futuras, recomenda-se a realização de estudos de casos a fim de verificar de que modo a GRH contribui para o desempenho ambiental, bem como a aplicação desse modelo junto a outros setores empresariais no Brasil e em outros países. Sugere-se, também, a inclusão de outras variáveis, no que diz respeito tanto às práticas de recursos humanos quanto à gestão ambiental. 


\section{REFERÊNCIAS}

ABIMAQ. Anuário 2011-2012, ABIMAQ Associação Brasileira da Indústria de Máquinas e Equipamento, Site Institucional. Disponível em <http://www.abimaq.org.br/> Acesso em 01 Out 2014.

BARRETO, L. M. T. S.; SILVA, M. P.; FISCHER, A. L.; ALBUQUERQUE, L. G.; AMORIN, W. AP. C. Emerging issues in human resources management: An analysis of academic production. Rev. Adm. UFSM, Santa Maria, v. 4, n.1, p. 215-232, 2011.

BRASIL. Lei $10.165 / 2000$. Altera a Lei $n^{\circ} 6.938$, de 31 de agosto de 1981, que dispõe sobre a Política Nacional do Meio Ambiente, seus fins e mecanismos de formulação e aplicação, e dá outras providências. Disponível em http:// www.planalto.gov.br/ccivil_03/leis/L10165. htm Acesso 10 Set 2012

CHAIB, E. B. D. Proposta para implementação de sistema de gestão integrada de meio ambiente, saúde e segurança do trabalho em empresas de pequeno e médio porte: um estudo de caso da indústria metal-mecânica. Dissertação (Mestrado em Planejamento Energético). Programas de Pós-Graduação de Engenharia da Universidade Federal do Rio de Janeiro, 2005.

COHEN, J. Statistical Power Analysis for the Behavioral Sciences. 2nd ed. New York: Psychology Press, 1988.

CNI/ABIMAQ. Confederação Nacional da Indústria. Associação Brasileira de Indústria de Máquinas e Equipamentos. A indústria de máquinas na era da economia verde / Confederação Nacional da Indústria. Associação Brasileira de Indústria de Máquinas e Equipamentos. - Brasília : CNI, 2012.

DAILY, B. F.; HUANG, S.C. Achieving sustainability through attention to human resource factors in environmental management. International
Journal of Operations \& Production Management, v. 21, n. 12, p. 1539-1552, 2001.

DUTTA, S. Greening people: a strategic dimension. ZENITH International Journal of Business Economics \& Management Research, v.2, n. 2, p. 143-148, 2012.

FAUL, F.; ERDFELDER, E.; BUCHNER, A.; LANG, A.G. Statistical power analyses using $G *$ Power 3.1: Tests for correlation and regression analyses. Behavior Research Methods, v. 41, p. 1149-1160, 2009.

FIERGS. Caderno Setorial Rio Grande Do Sul - metal mecânico. FIERGS. Estudos Técnicos, Cadernos Setoriais: Metal Mecânico, Unidade de Estudos Econômicos - UEE Sistema FIERGS. Gestão 2011/2014. Disponível em <http:// adesm.org.br/wp-content/uploads/2011/11/ Metal-Mec\%C3\%A2nico-FIERGS.pdf>. Acesso em 13 Out 2014.

FORNELL, C.; LARCKER, D. F. Evaluating structural equation models with unobservable variables and measurement error. Journal of Marketing Research, v. XVIII, p. 39-50, 1981.

FREITAS, W. R. S.; JABBOUR, C. J. C.; SANTOS, F. C. A. Continuing the evolution: towards sustainable HRM and sustainable organizations. Business Strategy Series, v. 12, n. 5, p. 226234, 2011.

GOOSEN, M. F. A. Environmental management and sustainable development. Procedia Engineering, v. 33, p. 6-13, 2012.

GRUMAN, J. A.; SAKS, A. M. Performance management and employee engagement. Human Resource Management Review, v. 21, n. 2, p. 123-136, 2011.

HAIR JR, J. F.; BLACK, W. C.; BABIN, B. J.; ANDERSON, R. E.; TATHAM, R. L. Análise multivariada de dados. 6 ed. São Paulo: Bookmam, 2009

HAIR JR. J. F.; RINGLE, C. M.; SARSTEDT, M. PLS-SEM: Indeed a Silver Bullet. Journal of 
Marketing Theory and Practice, v. 19, n. 2, p. 139-151, 2011.

HENSELER, J.; RINGLE, C. M.; SINKOVICS, R. R. The use of partial least squares path modeling in international marketing. New Challenges to International Marketing, Advances in International Marketing,v. 20, p. 277-319, 2009.

HENSELER, J.; SARSTEDT, M. Goodness-of-fit indices for partial least squares path modeling. Comput Stat, v; 28, p. 565-580, 2013.

ISO 14001. ABNT NBR ISO 14001. Sistemas de gestão ambiental - especificação e diretrizes para uso, 2004.

ISO 14031. ABNT NBR ISO 14031. Gestão Ambiental - avaliação de desempenho ambiental - diretrizes, 2004.

JABBOUR, C. J. C.; SANTOS, F. C. A. The central role of human resource management in the search for sustainable organizations. The International Journal of Human Resource Management, v.19, n. 12, p. 2133-2154, 2008.

Employees' empowerment and maturity levels of corporate environmental managementin companies: a framework. Rev. Adm. UFSM, Santa Maria, v. 6, n. 3, p. 497-510, 2013.

JABBOUR, C. J. C.; SANTOS, F. C. A.; NAGANO, $M$. S. Análise do relacionamento entre estágios evolutivos da gestão ambiental e dimensões de recursos humanos: estado da arte e surveyem empresas brasileiras. R.Adm., São Paulo, v.44, n.4, p.342-364, 2009.

Contributions of HRM throughout the Stages of Environmental Management: Methodological Triangulation Applied to Companies in Brazil. International Journal of Human Resource Management, v. 21, n. 7, p. 1049-1089, 2010.

JABBOUR, C. J. C.; TEIXEIRA, A. A.; JABBOUR, A. B.S. L. Treinamento ambiental em organizações com certificação ISO 14001: estudo de múltiplos casos e identificação de coevolução com a gestão ambiental. Produção, v. 23, n. 1, p. 80-94, 2012.

JABBOUR, C. J. C.; JABBOUR, A. B. L. S.; GOVINDAN, K.; TEIXEIRA, A. A.; FREITAS, W. R. S.; Environmental management and operational performance in automotive companies in Brazil: the role of human resource management and lean manufacturing. Journal of Cleaner Production, v. 47, p. 129-140, 2013.

JABBOUR, C. J. C.; JABBOUR, A. B. L. S.; TEIXEIRA, A. A.; FREITAS, W. R. S. Environmental development in Brazilian companies: The role of human resource management. Environmental Development, v. 3, p. 137-147, 2012.

JACKSON, S. E.; RENWICK, D. W. S.; JABBOUR, C. J. C.; MULLER-CAMEN, M. State-of-theArt and future directions for Green Human Resource Management: Introduction to the Special Issue. German Journal of Research in Human Resource Management, v. 25, n. 2, p. 99-116, 2011.

JACKSON, S. E.; SCHULER, R. S.; JIANG, K. Aspirational Framework for Strategic Human Resource Management. The Academy of Management Annals, v. 8, n. 1, p. 1-56, 2014.

LATAN, H.; RAMLIDAQUI, N. A. The Results of Partial Least Squares-Structural Equation Modelling Analyses (PLS-SEM). Dec. 2013 Disponívelem:http://ssrn. com/abstract=2364191 orhttp://dx.doi. org/10.2139/ssrn.2364191

LIEBOWITZ, J. The Role of HR in achieving a sustainability culture. Journal of Sustainable Development, v. 3, n. 4, 2010.

MADSEN, H.; ULHOI, J. P. Greening of human resources: environmental awareness and training interests within the workforce. Industrial Management \& Data Systems, v. 101, n. 2, p. 57-65, 2001.

MALHOTRA, N. Pesquisa de marketing: foco 
na decisão. 3 ed., São Paulo, Pearson, 2012.

MANDIP, G. Green HRM: people management commitment to environmental sustainability. Research Journal of Recent Sciences, v. 1, p. 244-252, 2012.

MASSOUD, J. A.; DAILY, B.F.; BISHOP, J.W. Reward for environmental performance: using the Scanlon Plan as catalyst to green organizations. Int. J. Environment, Work place and Employment, v. 4, n.1, p.15-31, 2008.

MATOS, S. QUELHAS, O. Organizações humanamente sustentáveis: estudo de caso em Organizações de base tecnológica, um foco na gestão de Pessoas. RGSA - Revista de Gestão Social e Ambiental, v. 2, n. 2, p. 51-68, 2008.

MULLER-CARMEM, M; JACKSON, S.; JABBOUR, C.J.C; RENWICK, D. Green Human Resource Management. Zeitschriftfür Personal forschung, v. 24, n. 1, p. 95-96, 2010.

MURILLO-LUNA, J. L.; GARCÉS-AYERBE, C.; RIVERA-TORRES, P. Barriers to the adoption of proactive environmental strategies. Journal of Cleaner Production, v. 19, n.13, p.1417-1425, 2011.

MUSTER, V.; SCHRADER, U. Green Work-Life Balance: A New Perspective for GHRM. German Journal of Research in Human Resource Management, v. 25, n. 2, p. 140-156, 2011.

OENNING JUNIOR, A. Avaliação de tecnologias avançadas para o reuso De água em indústria metal-mecânica. Dissertação (Mestrado em Engenharia de Recursos Hídricos e Ambiental, Universidade Federal do Paraná.Curitiba, 2006.

PERRON, G. M.; CÔTE, R. P.; DUFFY, J. F.Improving environmental awareness training in business. Journal of Cleaner Production, $v$. 14, n. 6-7, p. 551-562, 2006.

RENWICK, D. W. S.; REDMAN, T.; MAGUIRE, S. GHRM: A review, process model, and research agenda. Working Paper Series 08-01, The
University of Sheffield, UK, 2008. Disponível em: http://www.shef.ac.uk/management/ staff/profile/renwick.html. Acesso em: 24/02/2012.

RENWICK, D. W.S.; JABBOUR, C. J. C.; MULLERCAMEN, M.; REDMAN, T.; WILKISON, A. Green (Enviromental) HRM. Call for papers, for a special issue of the. The International Journal of Human of Human Resource Management, v. 23, n. 16, p. 3498-3499, 2012.

RENWICK, D. W.S.; REDMAN, T.; MAGUIRE, S. Green Human Resource Management: A Review and Research Agenda. International Journal of Management Reviews, v. 15, n.1, p. 1-14, 2013.

RIMANOCZY, I.; PEARSON, T. Role of HR in the new world of sustainability. Industrial and Commercial Training, v. 42, n. 1, p. 11-17, 2010.

RINGLE, C. M.; SILVA, D.; BIDO, D. modelagem de equações estruturais com utilização do Smartpls. Brazilian Journal of Marketing, Ed. Especial, v. 13, n. 2, p. 56-73, 2014.

SARKIS, J. The adoption of environmental and risk management practices: Relationships to environmental performance. Ann Oper Res,v. 145, 367-381, 2006.

SEBRAE. Santa Catarina em Números: metal mecânico / Sebrae/SC. Florianópolis: Sebrae/ SC, 2010.68 p.

SENAI. Departamento Regional do Paraná. Rotas estratégicas para o futuro da indústria paranaense: Roadmappingde Metal Mecânica - horizonte de 2018. / SENAI. Departamento Regional do Paraná. - Curitiba: SENAI/PR, 2008.58p Disponível em <http://www.fiepr. org.br/observatorios/uploadAddress/Metal_ mecanico[48640].pdf> . Acesso em: 25 Abr 2014

SOUZA, M. F. S.; MOORI, R. G.; MARCONDES, R. C.O que o cliente de Bens Industriais Valoriza na Relação com os seus Fornecedores:o Caso de Empresas do Setor Metal Mecânico. RAC, v. 8, n. 1, p. 35-54, 2004. 
SPERANDIO; S. A.; GASPAR, M. A. Gestão Socioambiental em Empresas Industriais. Rev. Adm. UFSM, Santa Maria, v. 2, n. 1, p. 21-40, 2009.

SROUFE, R.;LIEBOWITZ,J.;SIVASUBRAMANIAM, N.; DONAHUE, J. F. Are You a Leader or a Laggard? HR's Role in Creating a Sustainability Culture. People \& Strategy, v. 33, n. 1, p. 3442, 2010.

SUDIN, S. Strategic GHRM: A proposed model that supports Corporate Environmental Citizenship. In.: 2011 International Conference on Sociality and Economics Development IPEDR, Singapore, v. 10, 2011.

SYNODINOS, N. E. The "art" of questionnaire construction: some important considerations for manufacturing studies. Integrated Manufacturing Systems, v. 14, n. 3, p. 221237, 2003.

TAYLOR, S.; EGRI, C.; OSLAND, J. HRM's Role in Sustainability: Systems, Strategies, \& Practices. Human Resource Management, call for papers, 2012.

TENENHAUS, M; VINZI, V. E.; CHATELIN, Y.; LAURO, C. PLS path modeling. Computational Statistics \& Data Analysis, v. 48, p.159- 205, 2005.

TEIXEIRA, A. A. Treinamento ambiental em organizações brasileiras: estudo de múltiplos casos. Dissertação de mestrado. Faculdade de Engenharia de Bauru, Universidade Estadual Paulista Júlio de Mesquita Filho, Unesp, Campus de Bauru, 2010.

WEHRMEYER, W. Greening people: human resource and environmental management. New York: Greenleaf, 1996.

WETZELS, M.; ODEKERKEN-SCHRÖDER, G.; OPPEN, C.V. Using PLS path modeling for assessing hierarchical Construct models: guidelines and empirical Illustration. MIS Quarterly, v. 33, n. 1, p. 177-195, 2009. 